\title{
Peer review deemed essential for 'blue skies' award scheme
}

London. Britain's Royal Society has given lukewarm support to Realizing Our Potential Awards (ROPA), a two-year-old government scheme to reward 'blue skies' researchers who collaborate with industry.

The society's report, published this week, endorses the general goal of the scheme. But it says that so far it seems to be having little impact on the volume of links between industry and academic institutions.

Nevertheless the Royal Society says that the ROPA scheme is "an important experiment" in public funding of science and should continue, but without any additional funds. The report says that the proportion of research council funding for universities to ROPAs should not exceed the present nine per cent until the quality of projects can be established.

Much of the report is taken up with an assessment of the government's decision not to use peer review to assess ROPAfunded projects, but to rely on evaluation by panels of industrialists. Announcing the ROPA scheme in February 1994, William Waldegrave, then Cabinet minister for science, said research proposals would by-pass peer review on the grounds that the system "disadvantaged" the types of speculative or unorthodox proposals the government was keen to encourage.

But the Royal Society report concludes that this alternative system appears to have failed, and supports the "full use of scientific referees". The authors say members of the panels of industrialists "felt restricted by not being allowed to give the same detailed scientific scrutiny to ROPA applications as was given to other [research funding] applications". In addition, evidence seemed to show that only a small proportion of speculative fundamental research projects had been funded.

The report also calls for an independent evaluation of the quality of ROPA proposals - once the project results are published to allay fears that funds have been awarded to "work of second-rate quality". The authors point out that proportionately more lower-quality projects have received ROPA funds than other research council grants.

The report suggests that the government needs to prioritize its objectives for ROPA, and that the research councils need to be given more flexibility in running the scheme. Entry requirements need to be adjusted to encourage participation from disciplines that do not strictly fall into the 'industry' category, as well as from younger scientists. But the report does acknowledge that the scheme requires less administration than other comparable grantawarding mechanisms.

\section{BSE transmission data pose dilemma for UK scientists}

London. Preliminary research results have confirmed fears that a small proportion of cows infected with bovine spongiform encephalopathy (BSE) can pass the disease on to their offspring, a conclusion that may directly affect the UK government's cattle slaughter programme.

The reported low rate of maternal infections - ten per cent in the offspring of BSEinfected cattle, and an estimated one per cent or more in the national herd - is not expected to affect overall BSE levels. Those "are falling at a rate of 40 per cent a year", according to the Ministry of Agriculture.

An announcement on maternal transmission of BSE had been expected (see Nature 381, 724; 1996). But its timing has fuelled further controversy in the United Kingdom and Brussels. Although the 12-member UK Spongiform Encephalopathy Advisory Committee (SEAC) discussed the results at a meeting on 19 July, the official government announcement was made on 1 August, days after parliament closed for the summer.

Opposition politicians are accusing the government of deliberately withholding the results. But Sir John Pattison, chairman of SEAC and vice-provost of University College London, says the time between SEAC's meeting and the announcement was spent reviewing the findings and drafting a statement for government. Pattison says SEAC assessed the data in less than two weeks. "I can't see how we could have acted faster."

This is the second time that SEAC has decided to release results before the scheduled completion of an experiment - or, indeed, its peer-reviewed publication in the scientific literature. The first occasion, when preliminary results suggested an association between the consumption of BSE-infected beef and a new strain of Creutzfeldt-Jakob disease, the human equivalent of BSE, helped to trigger the current beef crisis (see Nature 380, 273; 1996).

Francis Anthony, BSE spokesman for the British Veterinary Association, says he was "annoyed" when he heard that preliminary data had been released. "I believe there is a case for the scientists [conducting the experiments] to dig their heels in and say: 'we'll give the results when we're ready', otherwise they could be accused of doing bad science."

But Anthony acknowledges SEAC's dilemma. It had to act quickly in the interests of health, while ensuring the accuracy of the research being publicized, "particularly as I have been urging the government since 1988 to outlaw breeding from the offspring of BSE-infected cattle".

Sir Richard Southwood says the decision to release early data is justified on this occasion. Southwood, professor of zoology at the

\section{IMAGE \\ UNAVAILABLE \\ FOR COPYRIGHT REASONS}

Making the link: scientists faced a dilemma over the release of data before peer review.

University of Oxford, was the chairman in 1988 of the government's first advisory committee on BSE, whose recommendations led to the setting up of the maternal transmission experiments. "I know this is a thorny problem," he says. "But this is an important matter. In an ideal world we could wait. But science cannot operate in a vacuum from political, economic or social considerations."

Pattison says the results were released after SEAC members had assured themselves that waiting for further analysis would not have altered the thrust of the findings. "We couldn't just sit on this, and felt we had to tell the government. We knew that a culling policy would need to take account of maternal transmission," he says.

Pattison adds that, if SEAC had waited until the end of the experiments, it would have been accused of endangering public safety. But he acknowledges the dangers of creating an expectation among the public and politicians of the automatic early release of research results, and hopes it will not happen with further BSE-related experiments. "Peer review is absolutely critical; it is the essence of how we operate."

The latest findings come from a sevenyear project begun in 1989 at the government's Central Veterinary Laboratory in Weybridge, Surrey. The research compared rates of BSE infection in the offspring of two groups of cattle; analysis of the results has been complicated by the fact that, at an early stage in the experiments, many calves were fed with potentially infected feedstuff.

Of 333 calves born to mothers with BSE, 273 had died by 14 July. Initial histological examination showed that 42 suffered from BSE. An equivalent group was the offspring of BSE-free cattle. Thirteen of these animals had developed the disease. A comprehensive analysis of all the cases would have taken another year.

Ehsan Masood 